\title{
ASPECTOS DE MATRILATERALIDADE EM UM SISTEMA DE NOMINAÇÃO PATRILINEAR: EXPLORANDO FORMULAÇÕES DE GÊNERO E PESSOA ENTRE OS TUKANO
}

\author{
Fabiane Vinente dos Santos (D) $\triangle$
}


O artigo aborda a nominação das crianças filhas de pai não indígena (pehkasã, nome pelo qual os não indígenas são chamados em Tukano) e mãe Tukano. Chamadas de moregi (misturadas), estas crianças, pelos princípios de nominação, não teriam direito a um dos nomes do estoque masculino (bahseke wame), uma vez que seus pais são pehkasã e não possuem vinculação clânica nem nome para lhes legar. Contudo, a nominação destas crianças é possibilitada por um arranjo familiar - o pai da mãe (FM) atua como nominador matrilateral. Meu objetivo é explorar as consequências deste arranjo matrilateral, imprevisto no parentesco Tukano, e utilizar tal "inovação" para discutir alguns pontos sobre as transformações na questão de gênero no noroeste amazônico. Somente tomando a sério as diferenças de enfoque nas perspectivas masculinas e femininas, seria possível explicar o arranjo.

Palavras-chave: noroeste amazônico; Tukano; parentesco; onomástica; gênero.

\section{ASPECTS OF MATRILATERALITY IN A PATRILINEAL NAMING SYSTEM: EXPLORING GENDER AND PERSON FORMULATIONS AMONG THE TUKANO}

\section{ABSTRACT}

The article addresses the naming of children born to non-indigenous father (Pekasã, name by which non-indigenous are called in Tukano) and mother Tukano.

Called moregi (mixed), these children, who by the principles of naming would not be entitled to one of the names of the male stock (baseke wame), since their fathers are Pekasã and have no clan or name to bequeath them. However, the practice of naming these children is made possible by a family arrangement - the father of mother (FM) acting as a matrilateral nominator. My goal is to explore the consequences of this unforeseen matrilateral arrangement in Tukano kinship and to use such "innovation" to discuss some points about gender transformations in the Amazon Northwest. Only by taking seriously the issue of diverging male and female perspectives could such arrangement be explained.

Keywords: Northwest Amazon; Tukano;

\section{ASPECTOS DE MATRILATERALIDAD EN UN SISTEMA DE DENOMINACIÓN PATRILINEAL: EXPLORANDO FORMULACIONES DE GÉNERO Y PERSONA ENTRE LOS TUKANO}

\section{RESUMEN}

Este artículo aborda la denominación de los descendientes de padre no indígena (Pekasã, nombre Tukano para los no indígenas) y madre Tukano. Estos descendientes, llamados moregi (mezclados), no tendrían derecho a un nombre del repertorio masculino (baseri wame), según los principios de la nominación, ya que sus padres son Pekasã y no poseen vinculación a un clan ni un nombre que puedan heredar a sus hijos. A pesar de todo, la práctica de denominación de los hijos de no indígenas es posibilitada por un arreglo familiar - el padre de la madre (FM) actua como nominador matrilineal. Mi objetivo es explorar las consecuencias de este arreglo matrilineal imprevisto en el parentesco Tukano y utilizar tal "innovación" para discutir algunos puntos sobre las transformaciones en la cuestión del género en la Amazonia Noroccidental. Solo llevando en consideración las diferencias de enfoque en las perspectivas masculinas y femeninas será posible explicar este arreglo.

Palabras clave: Amazonia Noroccidental; Tukano; parentesco; onomástica; género. 


\section{APRESENTAÇÃO}

A região do noroeste amazônico é conhecida por abrigar um amplo sistema sociocultural, no qual estão inclusos os povos de língua Tukano um conjunto social amplo chamado de "Tukano Oriental” e formado não apenas pelos próprios Tukano $^{1}$ (que se autodenominam Ye'pâ Masa, ou Gente Terra), mas também pelos Tuyuka, Wanano, Siriano, Tatuyo, Barasana, Desana, Makuna, Waikanã, Cubeo, Arapaço, Miriti Tapuio, Karapanã etc. A literatura etnológica apresenta a estrutura social dos Tukano como um sistema aberto, formado por um número determinado de grupos linguísticos exogâmicos, que casam entre si, divididos em séries de clãs, ordenados hierarquicamente, de descendência patrilinear, com padrão de residência virilocal, aliança simétrica e terminologia de parentesco dravidiana (Cabalzar 2009:38). A comunidade de agnatos representa um compromisso de coesão cuja principal expressão é a Basari Wi'i, a Casa Comunal, centro da vida ritual, política e doméstica e fundamento de sua ordem social (C. Hugh-Jones 1979:40-53).

O casamento preferencial se dá a partir de um complexo sistema que articula divergência linguística ${ }^{2}$, nexos regionais ${ }^{3}$, equivalência de status dos clãs dos cônjuges e prescrições sobre o noivo e a noiva ideal - no caso dos homens, a esposa preferencial é uma prima cruzada patrilateral (FZD), seguida pela prima cruzada matrilateral (MBD).

A pertença clânica se dá pela via da patrilateralidade, e cada nova geração de Ye'pâ Masa recebe os mesmos nomes cerimoniais que já foram usados por gerações anteriores (S. HughJones 1979:249). Conforme Lasmar (2005:58), "para as meninas, de uma FFZ; para os meninos, de um FBB". Os nomes não ficam "gastos" com o uso constante, não são modificados ou acrescidos de outros nomes. Se tomarmos as narrativas de origem sobre a viagem da proto-humanidade na Cobra-Canoa $^{4}$ (CIPAC 2006), verificamos que o estado primordial de diferenciação de humanos é pautado por uma determinada quantidade de

1 A origem do nome "Tukano" vem da ave Ramphastidae, que, em língua tukano, é Dasea, um apelido supostamente dado pelas mulheres Desana, dado o hábito dos Tukano andarem sempre juntos, como estas aves.

2 Idealmente, um Tukano não poderia casar com uma mulher Tukano, devendo procurar sua esposa entre falantes de outras línguas, como o Desana, por exemplo (embora existam exceções entre os Tukano orientais, como os Makuna e Cubeo).

3 Conjuntos de grupos exogâmicos em um território específico, que intercambiam mulheres ao longo de várias gerações.

4 A Cobra-Canoa seria uma embarcação, descrita nas narrativas de origem, usada para abrigar as primeiras pessoas em seu processo de transformação. Lugares de poder onde a Canoa foi parando ao longo da viagem constituem-se em casas de transformação, associadas a nomes, potências e capacidades. 
nomes, chamados de "nomes de benzimento" (ou bahseke wame, em tukano), pertencentes aos ancestrais que desembarcam em terra: Doêthiro, Yu'upuri, Ye'parã, Se'êripĩhi, Akîto, Doê, Ki'mâro e Bu' ứ${ }^{5}$, atribuídos de acordo com a ordem de nascimento dos filhos de um mesmo genitor. Esta ordem, contudo, não é adotada automaticamente. Idealmente, o menino receberá o nome de seu avô paterno, de modo que dois conjuntos de nomes se alternarão entre as gerações masculinas. Para citar um exemplo que observei em campo, no caso dos primeiros filhos do sexo masculino - o primogênito -, este idealmente chamar-se-á Doêthiro em uma geração e Ye'pârasui na geração posterior. Os primeiros filhos, pela ligação mais próxima com os poderes primordiais da criação, recebem, através do nome, algumas prerrogativas de liderança.

Como os nomes são limitados, teremos em uma mesma comunidade pessoas diferentes partilhando os mesmos nomes com vários "Doêthiros", "Akîtos", "Bu'us" e assim por diante. A individualização se dá ao longo da vida e a partir de outros regimes de nominação paralelos, como o nome do registro civil e os apelidos. Dessa forma, haveria uma complementaridade entre endonímia (representada pelos nomes do estoque de cada grupo agnático) e exonímia (representada pelos nomes dos registros civis e apelidos), tensão para a qual Stephen HughJones (2002:54) já chamou a atenção. A morte é o grande final que desindividualiza novamente a pessoa, pois o princípio vital contido no nome idealmente retorna à sua casa de transformação de origem, enquanto seu corpo se deteriora (C. Hugh-Jones 1979:160).

Os nomes são, portanto, o elo de ligação mais forte da pessoa com seu clã de origem, funcionando como veículo de descendência, que, combinados com a língua, narrativas de origem e outros elementos, conformam a pertença agnática. Como esclarece Stephen Hugh-Jones (2002:47, grifo meu):
Os grupos exogâmicos tukano são convencionalmente descritos como "patrilineares", um termo que poderia ser tomado para sugerir que a identidade do grupo, o pertencimento a ele e a propriedade estão todos baseados em algum princípio abstrato e a priori de descendência. Na prática, as coisas funcionam de maneira oposta: é a propriedade material e imaterial e as noções de essência, propriedade e identidade que constituem os grupos e os tornam "patrilineares" - e aqui a língua, os nomes e a nominação passam para o primeiro plano.

5 Andrello (2006:261) aponta esses oito nomes como os primordiais. Em campo, ouvi variações deste conjunto, com alguns nomes a mais, outros a menos. Como antigamente as proles eram bem maiores do que as atuais, é razoável pensar que havia um número bem maior de nomes, embora a potência destes esteja sempre relacionada à ordem de saída dos ancestrais, seus primeiros donos, da Cobra-Canoa. Gabriel Gentil, por exemplo, aponta um conjunto mais amplo, pois aparecem também: Eremiri, Suegi, Seribi, Wesemi, Nari, Dia’wasomi, Ahusiri-Yaro, Yaí, Ahusiri, Ye’pâ Bairi, Suri, Nuhiro, Ye'pârasui, Ye’pârã, Ahu Ye’pâ, Ye’pâri, Suriã, Bu'usi, Ñahori, Ye’pasuriã, Sui, Ñami (Gentil 2005:105-106). 
O bahseke wame também possui funções terapêuticas e profiláticas, ligadas às potências xamânicas dos ancestrais: um bebê precisa ser nominado, pois só assim ele contará com o suporte que o liga à uma casa de transformação, à proteção e ao fortalecimento que ela outorga - e que é acionada pelos especialistas xamânicos - contra os ataques de entidades sobrenaturais agressoras. Foi graças a estas propriedades protetivas que o sistema onamástico dos povos de língua Tukano sobreviveu aos ataques que missionários cristãos empreenderam contra as instituições indígenas, como as próprias Casas Comunais, que foram substituídas do lado brasileiro por casas nucleares; ou contra os cultos de iniciação masculinos chamados genericamente de “Furupari”, paulatinamente substituídos por versões mais "condensadas" até quase desaparecerem em algumas áreas: enquanto as Casas e o culto do Jurupari sofreram sanções capazes de torná-los prescritos ou incipientes ao longo do século XX (Wright 1992), os circuitos dos nomes de benzimento continuaram a ser acionados e utilizados, pois os Tukano avaliavam que as tentativas de aboli-los deixavam crianças vulneráveis a doenças e a ataques de seres sobrenaturais, levando-as, eventualmente, a uma morte precoce.

Os nomes estariam ligados à parte "dura" dos corpos: os ossos, elementos primordiais da pessoa, formados a partir do sêmen masculino, enquanto as partes "moles" (sangue e carne) seriam relacionadas à contribuição feminina (C. Hugh-Jones 1979:115). Estas substâncias também estariam no cerne da formação da pessoa: C. Hugh-Jones (1979:220-222) e Andrello (2006:259) descrevem o útero como uma casa de transformação, que será acionada pelo sêmen. Várias são as imagens que também associam o útero a outros objetos, como ao cocho onde a bebida peeru é fermentada; à Cobra-Canoa, também ela um útero, que transporta a protohumanidade ao longo de seu processo de transformação; ou à própria Casa Comunal, onde as pessoas seriam "fermentadas" cotidianamente. Não por acaso, a palavra em tukano para "fermentar", pamiri, é a mesma que os Tukano traduzem como "transformar".

Apesar de as mulheres também possuírem seus próprios conjuntos de nomes, estes não apresentam as mesmas prerrogativas rituais dos nomes masculinos, não estando ligados à propriedade dos clãs. Nas palavras de Janet Chernela (1988:220, tradução minha), "a despeito da mulher participar de forma sincrônica [do parentesco] ligando diferentes grupos de descendência, elas estão fora da reprodução do modelo de descendência”. O pai atua como nominador, atribuindo o nome à criança e, com ele, várias capacidades sociais e espirituais. 
Nominar crianças com bahseke wame, portanto, representa mais do que uma prática classificatória ou meramente automatizada pela tradição: nela, estão envolvidas questões de ordem sociológica, cosmopolítica e da constituição da pessoa, sendo algo característico da condição humana.

Neste artigo, eu gostaria de explorar uma situação inusitada que aparentemente quebra várias dessas prescrições do sistema onomástico e social Tukano: a nominação das crianças filhas de pais não indígenas (pehkasãa, nome pelo qual os não indígenas são chamados em tukano) e mães Tukano. Chamadas de moregi ou "misturadas", estas crianças, pelas regras de nominação, não teriam direito a um bahseke wame - uma vez que seus pais são pehkasã e não possuem vinculação clânica nem nome para lhes legar. Entretanto, são comuns os casos de crianças que têm recebido nomes através de um expediente inusitado: a outorga de nomes pela linha matrilateral, com o pai da mãe (FM) atuando como nominador e dando um nome do estoque de seu clã.

Meu objetivo é explorar as consequências, dentro da lógica do sistema de parentesco Tukano, deste arranjo matrilateral imprevisto, e utilizar esta inovação para discutir alguns pontos sobre as transformações na questão de gênero. Utilizo como inspiração a discussão empreendida por Elvira Belaunde (2006), que reivindica o sangue como elemento da memória e do parentesco, e dialogo com algumas ideias de Marilyn Strathern $(1988,2001)$ cuja proposta, com base na Melanésia, indica que os postulados de gênero estão relacionados não a características estáticas, mas a capacidades circulantes entre corpos; finalmente, retomo algumas ponderações de Chernela (1988), segundo a qual a perspectiva feminina sobre determinados temas não necessariamente é convergente com a masculina em certos aspectos da cultura dos povos de língua Tukano.

Este artigo consiste em uma versão modificada de um dos capítulos de minha tese de doutorado (Santos 2018), com alguns aprofundamentos, frutos de insights posteriores. Portanto, as informações aqui apresentadas possuem como fonte dados que obtive durante o trabalho de campo, de observação participante, no médio Tiquié, na localidade de PariCachoeira, que abriga um Pelotão Especial de Fronteira do Exército Brasileiro (PEF) ${ }^{6}$, além de inferências estabelecidas por outros autores que trabalharam na região.

6 Pari-Cachoeira, no médio Tiquié, está localizada próximo à fronteira com a Colômbia, possui composição interétnica (Tukano, Tuyuka, Waikanã, Desana, Hupda e Barasana), mas é chefiada pelos Tukano do clã Ye’parã panicu. 


\section{RELACIONAMENTOS ENTRE MULHERES INDÍGENAS E MILITARES NÃO INDÍGENAS NO CONTEXTO DE UNIDADES MILITARES}

A questão da gravidez de jovens mulheres indígenas como fruto de relacionamentos com militares brancos é um fato recorrente na vida das comunidades que abrigam Pelotões Especiais de Fronteira do Exército Brasileiro (PEF), e mesmo das mulheres indígenas que vivem na área urbana de São Gabriel da Cachoeira. Passado o período de serviço do militar no pelotão, que raramente ultrapassa dois anos, os militares são transferidos para outras unidades e, caso seja vontade dos dois, leva a esposa ou companheira. Em Pari-Cachoeira, alguns casais foram formados, superando o período de serviço do homem no pelotão. Independentemente dos rumos que estas relações tomam - se chegam a tornar-se uniões consensuais, casamentos ou se terminam com a partida do homem -, há certa ansiedade em dimensionar as crianças frutos destes relacionamentos nas redes de parentesco locais.

$\mathrm{O} 6^{\circ}$. PEF instalado em Pari-Cachoeira na década de 1990 possibilita que anualmente uma quantidade determinada de homens brancos e indígenas de outras regiões circulem na comunidade. Dos cerca de trinta militares que servem no Pelotão, anualmente uma parte encerra seu período de serviço, enquanto outros chegam. Relacionamentos entre garotas locais e os forasteiros são comuns, transformando a localidade em um dos pontos de uma rede de circulação de homens que denomino prosaicamente de circuito de maridos em potencial, uma vez que os militares indígenas e não indígenas circulam pelas comunidades que abrigam PEF. Findo o tempo de serviço, alguns destes relacionamentos podem ter como consequência gestações e/ou casamentos ou uniões consensuais.

Mesmo que grande parte dos relacionamentos não se revertam em relações duradouras, as mulheres vislumbram nos homens brancos o acesso a um universo diferente daquele no qual foram criadas, o que envolve a vida na cidade e oportunidades de estudo e de trabalho. A perspectiva de que o casamento com o branco abriria as portas para outras formas de vivenciar a condição feminina para além dos valores consolidados pelas suas mães e avós, que tinham na roça e na criação dos filhos o sentido de realização pessoal, é muito própria das novas gerações de mulheres, especialmente as escolarizadas, que passaram pelas escolas das missões.

Não devemos, contudo, pensar que a atividade na roça se esgotou como fonte de satisfação para as mulheres. Muitas das indígenas que conheci, mesmo morando na cidade de São Gabriel e contando com salário, insistiam em manter sua 
"rocinha", ainda que em lugares longínquos, resistindo ao processo de expansão urbana, que engole ano a ano os terrenos de plantio nas periferias da cidade (Emperaire \& Eloi 2008). O que mudou foi que, atualmente, as novas gerações de mulheres possuem um leque mais amplo de opções, que lhes possibilita transitar em diversos espaços sociais, diferentemente de gerações anteriores de mulheres, cujo papel de circulação nas redes interclânicas lhes franqueava poucas opções fora deste âmbito.

Lasmar (2005:203) atribui a preferência pelos brancos como parceiros amorosos a vários motivos: um suposto maior traquejo por ocasião da conquista (a "lábia") seria o principal. Segundo a autora, o casamento com o branco opera uma espécie de "inversão da assimetria de valor entre germanos de sexos opostos e permite à mulher se reacomodar no sistema social" (Lasmar 2005:246), oferecendo a esta a possibilidade de, ao mesmo tempo, estar perto de sua família natal e da parentela cognática", atuando como veículo de continuidade de sua linha agnática" (Lasmar 2005:247). Entretanto, do ponto de vista dos homens
Tukano, além de não "devolverem" mulheres de quem as tomaram ${ }^{7}$, os surara (como os Tukano chamam os militares) possuiriam uma notória facilidade em consegui-las através da conquista, incorporando o papel de predadores. O enredo clássico das brigas entre soldados e indígenas civis, tanto na sede de São Gabriel quanto nas áreas de pelotão, passa geralmente pela disputa por alguma garota. Não possuindo irmãs para "dar em troca" nem participando dos circuitos sociais estabelecidos (dos quais as relações agnáticas são as mais importantes), os surara despertam a indignação dos jovens indígenas. Em uma festa comunitária, por exemplo, o comportamento tido como pouco respeitoso destes, somado ao consumo de bebidas, pode levar a episódios de violência e, não raramente, de agressão física.

\section{AS CRIANÇAS MISTURADAS}

A questão das crianças misturadas, ou como chamam em Tukano, moregi, aparece na literatura etnológica primeiramente no trabalho de Lasmar (2005:209), que explica que este termo não se relaciona com a categoria "caboclo", pois possui

7 Embora não seja extraordinário para um homem indígena ter um cunhado branco-militar, pela possibilidade de ter uma irmã casada com um deles, é extremamente raro que o inverso aconteça, ou seja, que um homem indígena case com uma mulher pehkasã no alto rio Negro. Uma das razões apontadas para isso são as diferenças de classe social e de gênero que serão atribuídas aos indígenas no "mercado matrimonial" das áreas urbanas do alto rio Negro. As chances de uma mulher ser aceita como esposa de um branco são bem maiores do que as de um homem indígena ser aceito como parceiro de uma mulher pehkasã. É importante lembrar, ainda, o papel das mulheres como expressões da alteridade dentro dos grupos agnáticos. Sua facilidade para obter parceiros entre os pehkasã não é compartilhada pelos seus irmãos e parentes homens. 
sentidos mais específicos para a socialidade Tukano. Existem categorias diferentes de moregi: se são filhos de branco com uma mulher Tukano são pehkasã moregi (brancos misturados), se são filhos de homens Tukano com mulher branca, são po'teriki hi moregi (índios misturados) (Lasmar 2005:210). As variações se distribuem entre dois polos: Tukano e pehkasã, e caracterizam-se pela incompletude. O po'teriki hi moregi não é Tukano da mesma forma que o pehkasã moregi não é branco. São "parcialmente" compostos assim. Essa noção de parcialidade é muito importante para meu argumento, como veremos mais adiante.

Alguns intelectuais indígenas têm insistido na crítica a estes arranjos domésticos, contestando o reconhecimento de filhos de mulheres indígenas com homens brancos como indígenas, que não teriam direito a nomes de benzimento nem a outras prerrogativas da condição indígena (Dutra 2009). Essa discussão tem se tornado ainda mais frequente em função do aumento de supostas vantagens advindas da identidade indígena no mundo moderno, como as ações afirmativas através do sistema de cotas para indígenas em processos seletivos de instituições públicas de ensino superior e programas sociais específicos para essas populações. Tal posição, porém, não é consensual, já que outros intelectuais indígenas têm investido em pensar as transformações no âmbito dos regimes de nominação agnáticos, como é o caso do trabalho de Barreto (2019:77), que, entre outras coisas, reflete sobre o uso de nomes cemimoniais Ye'pâ Masa por outros grupos étnicos em crianças que não são tukanas.

Ainda sobre as crianças misturadas, um olhar rápido a respeito destes casos poderia levar a crer, à primeira vista, que ter um bebê fora do que estabelecem as regras matrimoniais dos Tukano poderia configurar o que Strathern (2014:304), emprestando uma noção de Jacques Derrida, chamou de "cortar a rede", ou seja, interromper o fluxo de produção de relações estabelecido por uma relação. "Cortar", neste caso, é uma metáfora para "o modo como um fenômeno interrompe o fluxo de outros". Entretanto, se uma rede é cortada em um ponto, não significa que isso estanque seu fluxo. Pode ser que ele seja redirecionado. Se o bahseke wameé o vínculo da criança com o clã paterno, os nomes de batismo, onde constam o nome da mãe e do pai, acabam se constituindo em um elemento de introjeção de um cognatismo involuntário. Mesmo assim, permanece a questão: é possível afirmar que as uniões com os pehkasã sejam disruptivas em relação ao parentesco Ye'pâ Masa?

\section{COMO FAZER UM BEBÊ?}

Em primeiro lugar, é importante dar a devida atenção a como os Ye'pâ Masa explicam a concepção e o processo de gravidez. Como vimos na apresentação, a explicação hegemônica na literatura etnológica sobre a formação da 
criança pressupõe o papel menor da contribuição feminina, com o sangue e as partes moles do corpo relacionados à mulher, bem como a ideia de útero como um recipiente a ser preenchido. No entanto, eu gostaria de discutir isso a partir da perspectiva feminina. Para as mulheres, existem outros circuitos de saberes constituídos para explicar a composição da pessoa que nem sempre são convergentes com aqueles enunciados pela literatura etnológica, embora utilizem a mesma matriz de conhecimento. Esta distinção é importante porque sem ela não há como compreender o caso da nominação das crianças moregi. Utilizo as informações dadas por duas mulheres, esposas de Ye'pâ Masa: uma Desana e uma Tuyuka, já avós, durante nossas idas à roça, quando elas tentavam me fazer entender como é concebida uma criança.

A ideia de que são necessários vários intercursos para formar uma criança no ventre da mulher, comum nas terras baixas amazônicas, também está presente entre os Tukano. Mesmo no contexto atual, em que as explicações biomédicas sobre óvulos e espermatozoides orientam os discursos de professores e dos jovens escolarizados, os mais velhos defendem que a gravidez é o resultado de vários encontros sexuais.

Não seria correto dizer que a visão feminina sobre a formação das crianças na barriga da mãe difere profundamente da masculina, mas é importante chamar atenção para o fato de que ela apresenta algumas ênfases importantes: a criança seria constituída em partes; seus principais componentes seriam fruto do wahpó - uma substância liberada durante o ato sexual. Em sua versão masculina, seria o sêmen, e na feminina, os líquidos de lubrificação vaginal. Cada um dos wahpó contribuiria com um aspecto do corpo do feto: ossos seriam fruto do acúmulo de wahpó masculino, enquanto carne e sangue seriam o resultado do wahpó feminino. A noção de wahpó também aparece nos dados de Azevedo (2009), colhidos entre as mulheres Tukano, Tariana e Waikanã, de Iauaretê.

Um trabalho recente (Barreto 2019), que teve como interlocutores uma parteira Tuyuka e um benzedor Miriti-Tapuio, também aborda o aspecto de complementaridade entre homens e mulheres na formação do bebê. Na minha opinião, essa leitura foi possível por conta da interlocução com a mulher, o que possibilita que se visualize melhor este aspecto em relação a trabalhos que possuem interlocutores exclusivamente masculinos. Ainda sobre a etnografia de Barreto (2019), é importante comentar que este trabalho diverge da literatura sobre a ênfase no sangue (diî) como contribuição feminina ao corpo da criança, preferindo apontar o "líquido reprodutivo" masculino (conhecido, no senso comum, como İmi ki'î wasô) e feminino 
(Numió koô wasô). Estes líquidos, de valores equivalentes, são constitutivos do corpo do bebê no útero e ancorados na cosmopolítica de criação da humanidade através do leite e da espuma da planta conhecida como "buiu-buiu", que compõem o lago de leite, onde, mediante uma série de transformações, surgem as primeiras pessoas (Lasmar 2005:275-277).

A ênfase na complementaridade de homem e mulher na formação das crianças não é um ponto menos importante, como nos lembra Belaunde (2006), com uma contundente crítica ao viés masculino que perpassa pelas abordagens sobre parentesco ameríndio. Através da abordagem dos resguardos, dietas e reclusões, a manipulação do sangue emerge como prerrogativa feminina e lembrança incorporada nas mulheres do fatídico incesto primordial entre Lua e sua irmã, ação que acaba por estabelecer a memória do parentesco (Belaunde 2006:225-226). Ao mesmo tempo, o sangue e o sangrar aparecem como catalizadores da fertilidade e da comunicação entre os espaçostempo cosmológicos, promovendo diferentes potencialidades para homens e mulheres.

Uma monografia recente que aborda a complementaridade entre homens e mulheres nos regimes de conhecimento é a de Oliveira (2016), o que aponta para um maior investimento dos trabalhos etnográficos recentes no alto rio Negro nesse tópico. A autora revela que o nascimento de uma criança é um evento que envolve intensas negociações com alteridades ameaçadoras à mãe e ao bebê. Somente com a atuação conjunta do conhecedor com a parteira é que tais perigos podem ser superados.

Gostaria de me remeter brevemente, neste momento, às reflexões de Strathern sobre as crianças entre os Hagen, na Melanésia, tidas como objetificação de relações, carregando em si e externalizando componentes masculinos e femininos (Strathern 1988:112). No contexto etnográfico descrito, existiriam dois modos de troca praticados: o mediado, através de circulação de coisas - pedaços das pessoas que são extraídos de uns e absorvidos por outros -, e o modo não mediado, caracterizado pela atividade de produção (Strathern 1988:178). Uma criança seria o produto de um modo de troca não mediada: partindo sempre da ideia de que relações se constituem em processos de produção de efeito de um agente sobre outro; uma criança, assim como o alimento produzido, seria o próprio efeito da relação que carregaria em si partes dos seus produtores.

Este raciocínio se aplica perfeitamente à forma com que as mulheres Tukano encaram a questão de seus filhos concebidos com brancos. A ideia de dupla composição (masculina e feminina) é o que permite às mulheres Ye'pâ Masa que 
têm filhos de pai não indígena, os moregit, os considerar parcialmente indígenas e solicitar dos FM destas crianças o bahseke wame, para protegêlas dos perigos aos quais estão expostas a partir dessa pertença, fundamentada no componente "feminino" de seus corpos (Lasmar 2005:209-211).

Como visto, pelas regras formais de nominação, acionadas a partir do circuito patrilateral com a ação xamânica, essas crianças não teriam direito a um nome Ye'pâ Masa, mas as mulheres promovem a obtenção de nomes para seus filhos, utilizando como argumento sua própria contribuição no corpo destes: se são "metade" indígena, precisam de um nome por conta desta metade. Este entendimento da formação do feto encara a contribuição feminina no mesmo nível da masculina. Aparentemente, as mulheres Ye'pâ Masa estariam subvertendo as regras de transmissão dos nomes de benzimento e das prerrogativas clânicas a eles associadas, ao ignorar propositalmente o papel do pai (F), neste contexto específico, e considerar apenas o da mãe (M). Os anglófonos usam a expressão bypassing para descrever esta situação, que eu acho bem adequada aqui. Guardemos este ponto em mente.

Marilyn Strathern defende que, na Melanésia, homens e mulheres são fontes de metáforas sobre masculinidade e feminilidade. $\mathrm{O}$ gênero como atributo não seria fixo, mas sim uma capacidade presente nos corpos e ativada em contextos específicos: os eventos que tornariam essas capacidades manifestas por meio da diferenciação interna entre macho e fêmea. A sexualidade constituir-se-ia em uma ativação específica de um estado de gênero particular:

The shape that people's bodies and
minds take--whether they are seen
as male or female-becomes the focus
of their operations upon one another.
That is not the same as saying that
they are always in a sexually activated
state. On the contrary, sexuality is a
specific activation of a particular
gender state: for a person to encounter
another of 'opposite sex' means that
her or his own gender takes a singular
form. In this condition, one person
elicits a corresponding sexual form
in another. He is all-male or she all-
female, strictly with respect to that
other. When gender identity thus
becomes homogenized in a unitary,
single sex form, the person's internal
parts are in a same-sex relation with
one another. However, the outcome of
such activation, conceived as a product
of the relationship between partners,
takes another form: it embodies within
itself a cross-sex relation. A person's
gender may thus be imagined as dually
or multiply composed, and in this
androgynous state men and women
are inactive. In their dealings with one
another, persons alternate between
being conceived in a same-sex state or
a cross-sex one. They thus embody or
objectify social relations by evincing
them in either one or the other shape
(Strathern $1988: 183$ ).

É importante esclarecer que não penso que homens e mulheres sejam categorizações dispensáveis no alto rio Negro, e Strathern deixa claro, em seus escritos, que elas não são dispensáveis na Melanésia tampouco, mas gostaria de enfatizar a possibilidade apresentada pela autora 
de alternação entre a orientação para o próprio sexo do sujeito (que o separa do outro) e a orientação para o outro (que se combina com o dele), porque penso que ela é extremamente adequada para discutir a situação dos filhos de pais pehkasã que ganham nomes a partir de suas mães. Acredito que, no âmbito estrito desta relação de nominação, mulheres não estariam "manipulando" regras formais, mas sim eclipsando a contribuição dos pais, enquanto ativam suas próprias capacidades masculinas presentes também em seus próprios corpos de dupla composição (Strathern 2001:226).

No âmbito da relação sexual, capacidades femininas e masculinas presentes em homens $\mathrm{e}$ mulheres são "derramadas" e ativadas para que se gere uma criança. Nesta perspectiva, este bebê, andrógino em sua natureza, seria fruto de uma relação de sexo-cruzado, pois foi composto pela contraparte feminina de sua mãe e masculina de seu pai. Porém, algo acontece no ato de sua nominação: sua mãe avalia que o corpo deste bebê é "parcialmente" carente de proteções que somente o bahseke wame pode prover. Ele não está completamente imune a ataques espirituais [dohase], pois não é completamente pehkasã: parte dele, a parte que sua mãe lhe deu e que está no sangue e na carne, necessita do fortalecimento que a ligação com as vitalidades originais fornece. Então, o pai de sua mãe (FM), agindo como inseminador, eclipsa (ou bypass) o genitor e atribui a esta criança o nome de benzimento do patrimônio pertencente ao clã matrilateral.

Tal situação resvala em duas hipóteses interpretativas: a primeira, insatisfatória do ponto de vista do parentesco, é a de uma espécie de incesto, com o pai da mãe (FM) atuando como pai (F) da criança, já que ele forneceu o nome de seu próprio estoque clânico. A outra, que eu acredito ser mais interessante, é a de que a mãe, uma vez estabelecido que é composta ela própria de capacidades masculinas e femininas, estaria no ato da nominação ativando sua contraparte masculina, ao fornecer à criança, através de seu pai nominador, um nome que seria por direito de seus irmãos homens e dos filhos destes. O pai (FM) pode ser o nominador, mas o componente presente no corpo da criança que possibilita este vínculo é o feminino - sangue e carne.

Frente a estas questões, surge uma pergunta, que é colocada frequentemente nas conversas cotidianas dos homens Ye'pâ Masa aparentados ou não de crianças "misturadas" sobre esta situação: a nominação de crianças pela circulação de capacidades a partir de suas mães ameaçaria a renovação geracional? Lembremos que, para estes povos, o tempo é "achatado" nos rituais de iniciação, como "folhas empilhadas no chão da floresta", uma metáfora que S. Hugh-Jones captou 
entre os Barasana e que expressa com agudeza a concepção temporal dos Tukano:

\begin{abstract}
Os Barasana são completamente conscientes que a descendência implica profundidade de tempo, uma profundidade expressa em termos espaciais. Eles comparam a sucessão de gerações às folhas que se empilham sobre o chão da floresta. O fundo da pilha representa os primeiros ancestrais e o topo os que vivem hoje. Eles dizem que esta separação entre a sociedade contemporânea e o seu passado mítico é algo indesejável e perigoso que deve ser superado por meio de rituais. Eles dizem que o ritual, especificamente o rito he wi, casa de Jurupari, seu rito de iniciação, achata efetivamente a pilha de tal modo que cada geração de iniciados é posta em contato direto, e adotada pelos primeiros ancestrais, representados pelos instrumentos de Jurupari (S. Hugh-Jones 1979:5).
\end{abstract}

Strathern (2001) compara os processos de diferenciação primordial no noroeste da Amazônia com o dos Piro, do baixo Urubamba, pesquisados por Gow (1991:278), entre os quais as pessoas se identificariam como " mixed people", ou misturados, estabelecendo um movimento de constante expansão através da mistura contínua e da busca de novas diferenças, enquanto que, para os Barasana, a indiferenciação seria o estado original a partir do qual surgiu a necessidade de diferenciação. Poderíamos acrescentar, ainda: e no final, por ocasião da morte, quando os nomes retornam para suas casas de transformação anulando a individualidade dos mortos, a diferenciação é substituída pela indiferenciação novamente.
Frente à questão da nominação das crianças moregi, questiono se as mulheres não estariam reelaborando esta orientação de substituição contínua em substituição pela ideia de expansão, a partir das novas modalidades de nominação que instituem. Estas operações acabam "abrindo" o sistema, ao trazerem para dentro dele pessoas cujas capacidades estão sendo obtidas por vias diferentes dos tradicionais circuitos patrilaterais, uma vez que, ao invés de mulheres "vindas de fora", teríamos homens. Seriam as "descontinuidades" produzindo pessoas. Entendo que este não é um ponto consensual, especialmente entre os homens, mas é impossível não apreciar a série de questões interessantes que as mulheres, com sua criatividade, apresentam neste âmbito.

Esta posição diverge da de Lasmar (2005:211), quando ela cogita que a prática de nominação acionada pelas mulheres teria potencial disruptivo. Acredito que isso não ataca o sistema de parentesco Tukano, mas o reafirma. Ao "trazer para dentro" as crianças moregit, ao invés de excluí-las, as mulheres possibilitam que estes indivíduos participem do sistema sem desmontá-lo. Em campo, conheci pelo menos dois homens adultos nesta situação. Sua ascendência de pai pehkasã, que era conhecida na comunidade, não era impedimento para que eles fossem considerados Tukano. Essa situação parece apontar para uma diferença entre a forma como 
tais crianças são vistas a partir do contexto: nas comunidades ribeirinhas, as tensões do conflito de identidade não se fazem tão presentes quanto na área urbana, mas afirmar isso categoricamente demanda mais pesquisa.

Uma rede cortada, diz Strathern (2014), não estanca seu fluxo, apenas redireciona seu crescimento para outros lugares. As crianças nascidas nestas circunstâncias não ficarão deslocadas. Eventualmente, estas mulheres poderão casar novamente com um homem indígena, prescrito ou não pelas regras de parentesco. Seus filhos da primeira união poderão permanecer com os avós maternos e ser criados por estes como seus próprios filhos, ou poderão ficar com a mãe e ser adotados pelo seu novo marido.

\section{CONCLUSÃO}

$\mathrm{Na}$ etnologia do alto rio Negro, a vida feminina parece ter pouca "ação", quando comparada à pompa dos ritos de iniciação masculinos, às práticas de nominação e à transmissão de capacidades realizada através dos homens para seus descendentes masculinos. Às mulheres, restaria o cotidiano das roças, o cuidado com as crianças e com o preparo dos alimentos, ou seja, a vida doméstica, aspectos que acompanharam o debate da questão de gênero na etnologia amazônica nos últimos quarenta anos e que, recentemente, têm sido questionados (Lasmar 1996).
A imagem da mulher aparece, nesse sentido, como expressão da alteridade dentro do grupo agnático seja a mulher que vem de fora, através do casamento com um membro do clã, seja a irmã solteira que, um dia, irá casar e se mudar para a comunidade do marido, o que converge na representação dela como eterna estrangeira. Entretanto, a forma como o parentesco é operacionalizado revela algumas sutilezas que amenizam este aspecto (Chernela 1988). Excluídas dos ritos que reforçam os laços agnáticos, as mulheres não contaram com o mesmo interesse por parte das pesquisas realizadas na região, com exceção do trabalho de Christine Hugh-Jones (1979), Janet Chernela (1993 e passim) e mais recentemente, de Christiane Lasmar (2005), que reencontra essa temática em um exercício que atualiza as visões das etnografias clássicas a partir dos relatos das transformações que as indígenas experimentam na cidade.

O traço agnático dos modelos explicativos da organização social dos Tukano enfatizou o caráter masculino da constituição dos clãs e reflete-se em outras dimensões do modo de viver, a exemplo da Casa Comunal e do rito masculino das flautas do Jurupari (Miriaporã), através do qual, entre outras coisas, se dava a iniciação de meninos na vida adulta. Apesar da grande popularidade deste modelo, posteriormente ele enfrentou algumas contestações: um dos autores que ajudou a construir este paradigma e que depois dedicou-se a revê-lo foi 
Stephen Hugh-Jones (1995:230). Inspirado pela noção de "Casa", de Lévi-Strauss (Lévi-Strauss \& Lamaison 1987), S. Hugh-Jones contrapõe este retrato estável da estrutura social com o da tensão constante entre duas formas diferentes, mas complementares, de socialidade, cada uma delas baseada em uma leitura "generificada" da Baseke Wi'i: uma masculina, marcada por hierarquia, afinidade e assimetria, expressa nos rituais de iniciação masculina, e outra feminina, marcada por consanguinidade, partilha e igualitarismo, expressa principalmente no cotidiano doméstico, embora também comporte espaço para a expressão ritual pelos ritos de troca de dádivas nos rituais Po'osehe ${ }^{8}$. Esta forma de ver as coisas parece mais inclusiva no que diz respeito à mulher e mais interessante no que diz respeito a rendimentos teóricos. Não se nega a questão do antagonismo de gênero, entretanto este não é o ponto de chegada: busca-se olhar mais detidamente para a dinâmica da socialidade que envolve vitalidades femininas e masculinas em vários dos processos sociais.

Strathern apresenta um problema real sobre a diferença entre a percepção dos antropólogos acerca das instituições nativas e a forma como estas são expressas pelos nativos. Quando os homens afirmam que seus rituais são fundantes da ordem "social", esta é uma questão consensual ou apenas eles estão expressando suas próprias concepções sobre como eles gostariam que as coisas fossem? Os relatos masculinos sobre o papel de ritos iniciáticos e da dominação dos homens sobre as mulheres, por exemplo, são tomados de forma ambígua: ao mesmo tempo que os antropólogos veem estes relatos como expressão do desejo irrealizável dos homens em equivaler sua capacidade gerativa à das mulheres, esses mesmos relatos são tratados como evidência do papel dos homens na constituição da organização social dos coletivos humanos. Strathern (1998) chama a atenção para esta divergência no entendimento antropológico, no contexto da Melanésia:

The claims Highlands men make in
the context of their rituals have been
interpreted as strenuous assertions by
which they at once dominate women
and mystify themselves. To suggest
that a set of ideas has a mystifying
effect also suggests, of course, that
a real situation exists beyond them,
that the actors are incorrectly
apprehending reality. Consequently
there exists an interesting asymmetry
to these accounts. Men are regarded
as deluding themselves, but what they
attribute to women is taken by the
observer as real (Strathern 1988:99).

Simplificando: Strathern expõe a tendência dos antropólogos de tomarem as afirmações dos homens como as únicas capazes de fundamentar as explicações sobre a ordem social. Bellier (1993:517) já chamava a atenção para esta questão, afirmando que as mudanças nas análises sobre a questão de gênero na Amazônia estavam muito relacionadas

8 Rito de troca de dádivas, também conhecido pelo termo em nheengatu dabucuri. Tradicionalmente celebrado entre grupos afins que alternam os papéis de recebedores/doadores. 
ao julgamento do etnógrafo. Entre as abordagens que estão explorando outras possibilidades teóricas e conceituais, não posso deixar de citar, neste sentido, a leitura dos ritos de iniciação masculina a partir de uma abordagem stratherniana por S. Hugh-Jones (2001).

O primeiro trabalho que chamou a atenção para a necessidade de se levar em consideração a diferença entre o ponto de vista masculino e o feminino na interpretação das diferenças de gênero na Amazônia foi o do casal Murphy, entre os Mundurucu (Murphy \& Murphy 1974). Os Murphy consideravam cada sexo como um grupo social em si, ou seja, como duas unidades autoconscientemente solidárias, opostas uma à outra, e seu antagonismo mútuo seria expresso nos rituais masculinos. Apesar da importância da apresentação da diferença de perspectivas de acordo com o gênero, $\mathrm{o}$ trabalho dos Murphy foi criticado por ter optado pelo esvaziamento do conteúdo da contradição representada pelo paradoxo da assimetria de poder, ao invés de lidar com ela (Fausto 2001:245-246), provavelmente porque o paradigma teórico que orienta o trabalho, o do antagonismo sexual (Lasmar 1996:69-86), não permitiu que os autores fossem além desta leitura.

No noroeste amazônico, a leitura da Casa Comunal como entidade andrógina, proposta por Hugh-Jones (1993, 1995), assinala que é preciso escapar das explicações simples sobre a dinâmica entre os polos masculino e feminino, e olhar o gênero como fluxos de capacidades, e não como condição. Nesse sentido, lembro uma leitura ainda mais radical da Baseke Wi'i, a Casa Comunal, em termos de gênero: a de Beksta (1988:41), que destaca que a Casa Comunal possui duas entradas - uma frontal, masculina, e uma ao fundo, feminina. Sendo uma matriz do universo dos povos Tukano, a Casa é sustentada por um conjunto de colunas, cada uma delas possuindo um nome masculino primordial a partir da porta frontal, como se fossem pessoas. Segundo Beksta (1988), estes nomes mudam completamente se a pessoa entrar pela porta traseira, quando, então, as mesmas colunas terão nomes femininos. Temos, assim, um exemplo bem claro de que as perspectivas masculina e feminina não precisam ser idênticas, mas sua dinâmica ainda não foi devidamente apreciada nos estudos antropológicos.

Mulheres Tukano, ao se relacionarem com homens pehkasã, parecem orientar-se pelo princípio de captação de capacidades no exterior ao qual as mulheres já são relacionadas no sistema de parentesco Tukano (Chernela 1993). As crianças misturadas nominadas com bahseke wame constituem-se em aquisições, apesar dos protestos de quem tende a vê-las como concorrentes e usurpadoras de prerrogativas clânicas, exclusivas dos homens que as recebem dos seus pais. Como já insinuava Strathern (1988) para a Melanésia, este seria um problema dos homens, não das mulheres, que não veem problema em seus filhos ganharem o nome de benzimento Ye'pâ Masa, mesmo que supostamente, para seus irmãos, elas não tenham "direito" a ele. 


\section{REFERÊNCIAS}

Andrello, G. 2006. Cidade do índio: transformações e cotidiano em Iauaretê. São Paulo: Unesp/ISA; Rio de Janeiro: NUTI.

Azevedo, M. 2009. Saúde reprodutiva e mulheres indígenas do Alto Rio Negro. Caderno CRH 22(57):463477. DOI: http://dx.doi.org/10.1590/S0103-49792009000300003.

Barreto, S. S. 2019. Relato de uma experiência do benzedor e da parteira sobre a concepção, gestação e nascimento da criança. Dissertação de Mestrado, Programa de Pós-Graduação em Antropologia Social, Universidade Federal do Amazonas, Manaus.

Beksta, C. 1988. A maloca Tukano-Desana e seu simbolismo. Manaus: Governo do Estado do Amazonas.

Belaunde, L. E. 2006. A força dos pensamentos, o fedor do sangue: hematologia e gênero na Amazônia. Revista de Antropologia 49(1):205-243. DOI: http://dx.doi.org/10.1590/S0034-77012006000100007.

Bellier, I. 1993. Réflexions sur la question de genre dans les sociétés amazoniennes. L'Homme (126128):517-526.

Cabalzar, A. 2009. Filhos da Cobra de Pedra: organização social e trajetórias tuyuka no Rio Tiquié (Noroeste Amazônico). São Paulo: Edunesp/ISA; Rio de Janeiro: Nuti.

Chernela, J. 1988. Some considerations of myth and gender in a Northwest Amazon Society, in Dialectics and gender: anthropological approaches. Editado por P. Randolph, D. Schneider, e M. Diaz, pp. 67-79. Boulder: Westview.

Chernela, J. 1993. The Wanano Indians of the Brazilian Amazon: a sense of space. Austin: University of Texas Press. 
Coordenação Indígena de Pari-Cachoeira (CIPAC). 2006. Kumuá Nâ̂ Uúkuse Basesé: origem do mundo e da humanidade. A sabedoria dos ancestrais Tukano do Rio Tiquié. Recife: Associação Saúde Sem Limites.

Dutra, I. F. 2009. A lei de auto-identificação indígena: o ser indígena do alto rio Negro. Comunicação apresentada na XV Reunião do Conselho Diretor da FOIRN. São Gabriel da Cachoeira, 13 a 15 de maio de 2009. (mimeo.).

Emperaire, L., e L. Eloi. 2008. A cidade, um foco de diversidade agrícola no Rio Negro (Amazonas, Brasil)? Boletim do Museu Paraense Emílio Goeldi. Ciências Humanas 3(2):195-211. DOI: http://dx.doi. org/10.1590/S1981-81222008000200005.

Fausto, C. 2001. As formas na História, in: Inimigos fiéis: História, guerra e xamanismo na Amazônia, pp. 175-248. São Paulo: Edusp.

Gentil, G. 2005. O Povo Tukano: cultura, história, valores. (Coleção Autores Indígenas). Manaus: Edua.

Gow, P. 1991. Of mixed blood: kinship and history in Peruvian Amazonia. Oxford: Clarendon Press.

Hugh-Jones, C. 1979. From the milk river: spatial and temporal processes in Northwest Amazonia. Cambridge: Cambridge University Press.

Hugh-Jones, S. 1976. 'Como as folhas no chão da floresta...': espaço e tempo no ritual Barasana. Simpósio Tempo social nas sociedades das Terras Baixas Sulamericanas. [Tradução para o português de Fernanda Araújo Costa]. XLII Congresso Internacional de Americanistas. 2 a 9 de setembro, 1976.

Hugh-Jones, S. 1979. The Palm and the Pleiades. Cambridge: Cambridge University Press. 
Hugh-Jones, S. 1993. Clear descent or ambiguous houses? A re-examination of Tukanoan social organization. L'Homme (126-128):95-120.

Hugh-Jones, S. 1995. Inside-out and back-to-front: the androgynous house in Northwest Amazonia, in About the house. Lévi-Strauss and beyond. Editado por J. Carsten e S. Hugh-Jones, pp. 226-252. Cambridge: Cambridge University Press.

Hugh-Jones, S. 2001. The gender of some Amazonian gifts: An experiment with an experiment, in Gender in Amazonia and Melanesia. Editado por T. Gregor e D. Tuzin, pp. 245-278. Berkeley: University of California Press.

Hugh-Jones, S. 2002. Nomes secretos e riqueza visível: nominação no noroeste amazônico. Mana 8(2):45-68. DOI: http://dx.doi.org/10.1590/S0104-93132002000200002.

Lasmar, C. 1996. Antropologia feminista e etnologia Amazônica: a questão do gênero nas décadas de 70 e 80. Dissertação de Mestrado, Departamento de Antropologia Social, Museu Nacional/Universidade Federal do Rio de Janeiro, Rio de Janeiro.

Lasmar, C. 2005. De volta ao Lago de Leite. Gênero e transformação no Alto Rio Negro. São Paulo: Unesp/ ISA; Rio de Janeiro: NUTI.

Lévi-Strauss, C., e P. Lamaison. 1987. La notion de maison: entretien avec C. Lévi-Strauss. Terrain (9):34-39. DOI: http://dx.doi.org/10.4000/terrain.3184.

Murphy, Y., e R. Murphy. 1974. Women of the forest. New York: Columbia University Press.

Oliveira, M. S. 2016. Sobre casas, pessoas e conhecimentos: uma etnografia entre os Tukano Hausirõ e Ñahuri Porã do Médio Rio Tiquié, Noroeste Amazônico. Tese de Doutorado, Programa de PósGraduação em Antropologia Social, Universidade Federal de Santa Catarina, Florianópolis. 
Strathern, M. 1988. The gender of the gift: problems with women and problems with society in Melanesia. Berkeley: University of California Press.

Strathern, M. 2001. Same-sex and cross-sex relations: some internal comparations, in Gender in Amazonia and Melanesia. An exploration of the comparative method. Organizado por T. Gregor e D. Tuzin, pp. 221-244. Berkeley: University of California Press.

Strathern, M. 2014. Cortando a rede, in O efeito etnográfico e outros ensaios, pp. 295-319. São Paulo: Cosac Naif.

Santos, F. V. O arco e o fuzil: a convivência entre os Ye'pâ-Masa e os militares do Exército Brasileiro em Pari-Cachoeira, Noroeste Amazônico. Tese de Doutorado, Programa de Pós-Graduação em Antropologia Social, UNICAMP, Campinas.

Wright, R. 1992. História indígena do noroeste da Amazônia: hipóteses, questões e perspectivas, in História dos índios no Brasil. Organizado por M. Carneiro da Cunha, pp. 253-266. São Paulo: FAPESP/ Companhia das Letras/SMC. 